\title{
The Effect of Developing the Pragmatic Competence of Kurdish EFL Students on Their Conversational Interaction Ability
}

\author{
Walaa' Jabbar Katti'
}

English Language Dept., College of Languages and Human Sciences, University

Of Garmian, Kurdistan Region, Iraq

Email:walaa.jabbar@garmian.edu.krd

\section{Abstract}

Language is the most powerful means of communication we have- but only if it is used well. Otherwise, it can be just as much as a barrier for the communication. Our language is probably the most sensitive side of us.

Moreover, in order to help the students to master the English language it is not enough to have a broad vocabulary, errorless pronunciation and a profound knowledge of grammatical structures. Students need to be able to make judgments in terms of what is socially appropriate in a particular situation where one is communicating with a particular interlocutor and performing a specific type of speech act. Thus, to be successful in this area of language use one needs to have developed pragmatic competence

As a matter of fact, through many years of teaching college students in different grades, it has been proved that they often lack necessary pragmatic competence; that is, they are not aware of the social, cultural, and discourse conventions that have to be followed in various situations. Relatively, less attention has been paid to how classroom-based instruction can contribute to the pragmatic development of foreign language learners. Thus, the present research paper aimed at investigating the effect of developing students' pragmatic competence through the focusing on two speech acts, greeting and invitation. In addition, this research attempts to find out whether there will be any effective influence after developing students' pragmatic competence on their conversational interaction ability.

In order to achieve the aims of this research and test its hypotheses, the researcher has constructed an achievement pre-test and post-test. The sample of the present research will be students of English department in college of languages and Human Sciences at Garmian University.

\section{Introduction}

Pragmatics is the study of language use which offers a complementary perspective on language, providing an insight into the linguistics choices that users make in social 
situations. Consequently, Yule (1988: 91) believes that pragmatics is concerned with aspects of meaning in language, specifically with the characterization of speakermeaning. In many ways, pragmatics is the study of 'invisible' meaning, or how we recognize what is meant even when it isn't actually said or written.

Clark (2007:50) also agrees that pragmatics is concerned with unspoken or implicit meanings in language.

To clarify, it is the case that people do not always say what they mean. For example, when somebody says 'It's warm in here' the speaker may mean Can you open the window? Thus people may mean something quite different from what their words say.

According to Yule (1996) pragmatics is a concerned with the study of meaning as communicated by a speaker and interpreted by a listener. Jacob (2oo1) also believes that "Pragmatics is the study of the condition of human language uses as these are determined by the context of society

Pragmatics focuses on cultural variations in the ways people use and interpret discourse. As Bonvillian (1993: 85) puts it:

'Understanding meaning is necessarily contextual, situating speech in interpersonal and cultural context. All cultures provide rules for appropriate communicative interaction, defining behaviors that should occur, that may occur and that should not occur in given contexts'.

In order to function most fully within a society, knowledge of language structures is simply not enough. Knowledge of how to use a language to best convey and interpret intended meaning is necessary as well. The emphasis on developing pragmatic competence, seem to be a common denominator among language learners who acclimate easily into the target culture.

Consequently, while communicative competence and grammatical competence are explicitly taught and developed in the EFL classroom, developing pragmatic competence is often overlooked. The present study hypothesized the following:

1) The positive effect of developing students' pragmatic competence on their language learning.

2) Developing the students' conversational interaction ability through developing their pragmatic competence.

\section{Pragmatic Competence}

Knowledge of language alone does not adequately prepare learners for effective and appropriate use of the target language. Richard and Renandya, 2002: 207) state that 
learners must have competence which involves knowing what is expected socially and culturally by users of the target language; that is learners must acquire the rules and norms governing the appropriate timing and realization of speech acts. As well as understanding the sociolinguistic sides of language helps learners know what comments are appropriate, how to ask questions during interaction, and how to respond nonverbally according to the purpose of the talk. According to Crystal (1988: 48) 'if you choose to say something, there are all kinds of factors which constrain what you will say and how you will say it'. In fact, there is no theory prevents you to say anything you like, but in practice, you follow a wide range of social rules governing the way you speak.

Communicative language pedagogy and research into communicative competence have shown that language learning exceeds the limits of memorizing vocabulary items and grammar rules ( Canale, 1983). Pragmatic competence, although sometimes in disguise, has been a part of the models describing communicative competence.

Pragmatic competence is not a piece of knowledge additional to the learners' existing grammatical knowledge, but it is an organic part of the learners' communicative competence (Kasper, 1997). Communicative competence, on the other hand, is a term for communication in spite of language, rather than communication through language (Higgs and Clifford, 1982:61).

Edwards and Csizer (2001) believes that pragmatic competence can be defined as the knowledge of social, cultural, and discourse conventions that have to be followed in various situations.

Pragmatic competence is the way learners manipulate language in order to meet communicative goals (Brown, 1994: 228).

It is good mentioning that linguists such as Bardovi-Harlig and et al (1996:324) highlight the importance of pragmatic competence and point out the consequences of the lack of this competence:

'Speakers who do not use pragmatically appropriate language run the risk of appearing uncooperative at the least, or, more seriously, rude or insulting. This is particularly true of advanced learners whose high linguistic proficiency leads other speakers to expect concomitantly high pragmatic competence.'

Successful communication necessitates pragmatic competence, which changes form and realization from language to language. The implications of such an assertion are that when we teach a foreign language, there is a good chance that learners are faced with quite different conversational strategies in the target language from their mother tongue. Therefore, they may perform transfers from their language and these may 468 | acadj@garmian.edu.krd Vol.5, No.4 (August, 2018) 
turn out to be inappropriate in the target language context. Besides, they may simply have much difficulty to learn them properly because of their mother tongue interference.

\section{Speech Act Theory}

Our understanding of the underlying or unstated rules that govern communication owes a great deal to a particular theory of language known as speech act theory. Speech act theory was originated by the philosopher John Austin (1962), expanded by Searle (1969), and developed further by Grice (1975). According to Clark (2007: 57), the speech act theory is based on the belief that language is often used to perform actions and on how meaning and action relate to language. As Austin (1962: 100) says:

'The words used are to some extent to be explained by the context in which they are designed to be or have actually been spoken in a linguistic interchange'.

However, Yule (2006:118) claims that we can define a speech act as the action performed by a speaker with an utterance. If you say, Good morning, or Would you like to come to my birthday party, you are not just speaking, you seem to be performing the speech act of 'greeting' and 'invitation'.

As humans we communicate verbally and non-verbally. Austin (1962) called verbal communication a speech act and argued that speech acts performed three different acts, these are:

1) The locutionary act corresponds to the act of saying something. It involves uttering certain noises in a particular grammatical construction with a more or less definite sense of reference.

2) The illocutionary act is the act performed in saying something. It reflects the speaker's intent in uttering a sentence.

3) The perlocutionary act is the act performed by saying something. It involves the effect that the speaker has on her/him listener when uttering the sentence (Cark: 2007:57).

Speech acts are verbal actions that accomplish something: we greet, insult, compliment, flirt..etc.. Austin (1962) believes that there are many types of speech acts, such as:

1) Representatives: here the speaker asserts a proposition to be true, using such verbs as: affirm, believe, conclude, deny, report.

2) Directives: here the speaker tries to make the hearer do something, with such words as: ask, beg, challenge, command, dare, invite, insist, request. 
3) Commissives: here the speaker commits himself (or herself) to a (future) course of action, with verbs such as: guarantee, pledge, promise, swear, vow, undertake, warrant.

4) Expressives: the speaker expresses an attitude to or about a state of affairs, using such verbs as: apologize, appreciate, congratulate, deplore, detest, greet, regret, thank, welcome.

5) Declarations the speaker alters the external status or condition of an object or situation, solely by making the utterance: I now pronounce you husband and wife, I sentence you to be hanged by the neck until you be dead, I name this ship...

Concerning the present study, directives (invitations) and expressives (greetings) speech acts have been chosen as a tool to develop the students' pragmatic competence.

\section{The Teachability of Pragmatic Competence}

Can pragmatic competence be taught? This question has inspired a number of research projects exploring the role of instruction in learners' pragmatic development. kasper ( 1997) argues that while competence can not be taught, students should be provided with opportunities to develop their pragmatic competence:

Competence is a type of knowledge that learners possess, develop, acquire, use or lose. The challenge for FLT is whether we can arrange learning opportunities in such a way they benefit the development of pragmatic competence in $F L$.

A number of studies have explored how English language textbooks present speech acts (see Bardovi-Harling and et al (1996) on closings; Boxer and Pickering (1995) on compliments; Edwards and Csizer (2001) on openings and closings; and Richards (2000) on invitations. Theses studies concluded that textbooks usually fail to provide the necessary and appropriate input in speech acts, and the material they do present often differs from real life speech.

\section{Textbook Materials Need to be Flexible}

Although language is a social practice, learning a language is largely individual process as learners seek to integrate newly perceived information into their existing language system. It is essential for teachers to recognize the different backgrounds, experiences, and learning styles that students bring to the language classroom. In other words, it is to a large extent the learners, not the teachers, who control what is learnt since it is they who selectively oganise the sensory input into meaningful wholes. 
In fact, the ultimate goal of the learning process is that the input from the materials provides linguistic and cultural preparation before or in parallel with, the learnergenerated language. As O'Neill (cited in Rossner and Bolitho, 1990: 155-156)

Textbooks can at best provide only a base or a core of materials.... A great deal of the most important work in a class may start with the textbook but end outside it, an improvisation and adaptation, in spontaneous interaction in the class, and the development of that interaction.

According to Wright (1987) we teach with, rather than through, materials, thus being free to improvise and adapt in response to learner feedback. Effective teaching materials, by providing cultural and linguistic input and a rich selection of integrated activities, are thus a professional tool which can actually assist to be more responsive, both by leaving them time to cater to individual needs and by expanding their teaching repertoire. Learners, too, can benefit from access to the materials used in class, and this allows them to put on their learning.

The teachers' challenge is to maintain the balance between providing a coherent learning experience which scaffolds learner comprehension and production, and modeling effective strategies without losing responsiveness to the unique situation and needs of each learner. The textbook writers' challenge, on the other hand, is to provide materials which support teachers and learners, and present ideas for tasks and the presentation of language input without becoming prescriptive and undermining the teacher's and the learner's autonomy ( Richard and Renandya, 2002: 88). Accordingly, textbook materials need to be flexible to cater to individual and contextual differences.

However, the role of textbooks in raising students' pragmatic awareness is more important. It is difficult to give clear suggestions for improving pragmatic input in textbooks, particularly because textbooks are usually targeted to an international audience. Boxer and Pickering (1995) underlined the importance of building teaching materials on spontaneous speech and not relying on native speaker intuition, which may be misleading at times. Enriching classroom input with real-world materials, such as recordings of native speaker conversations, radio programs, can be beneficial. To provide sufficient pragmatic input for the students, it is also important to supplement textbooks that focus on pragmatics. This will give students firsthand experience in issues of pragmatic competence and deepen their understanding by letting them discover the rules themselves.

In practical terms, the present research support the idea that language classrooms should have a dual focus- not only on teaching language content, but also on developing learning processes. 


\section{How to Communicate Effectively?}

To communicate effectively, language learners need to become proficient in using, not just, the semantic, syntactic, lexical, morphological and phonological elements of the language being learnt. They also need to understand its pragmatics use.

It should be noted that learning to speak a foreign language requires more than knowing its grammatical and semantic rules. Learners must also acquire the knowledge of how native speakers use the language in the context of structural interpersonal exchange, in which many factors interact (Richard and Renandya, 2002: 204). However, speaking a language is especially difficult for foreign language learners because effective oral communication requires the ability to use the language appropriately in social interactions.

Accordingly, diversity in interaction involves not only verbal communication, but also paralinguistic elements of speech such as stress and intonation, nonlinguistic elements such as postures and facial expression. In addition, "there is tremendous variation cross-culturally and cross-linguistically in specific interpretations of gestures and body language" (Brown, 1994: 241).

\section{Sociocultural Factors and EFL Learners' Oral Communication}

Many cultural characteristics of a language affect FL learning. From a pragmatics perspective, language is form of social action because linguistic communication occurs in the context of structured interpersonal exchange and meaning is thus socially regulated (Dimitracopoulou, 1990). In other words, "shared values and beliefs create the traditions and social structures that bind a community together and are expressed in their language" ( Carrasquillo, 1994: 55).

As a matter of fact, culture plays an instrumental role in shaping speakers' pragmatic competence, which is related to the appropriate use of language. Generally, Richards and Renandyas (2002) agree that appropriateness is determined by each speech community . In other words, it defied by the shared social and cultural conventions of a particular group of speakers. Therefore, it is essential to recognize different sets of culturally determined rules of communication. Just as Brown and Yule (1983:40) say, "a great number of cultural assumptions which would be normally presupposed, and not made explicit by native speakers, may need to be drawn explicitly to the attention of speakers from other cultures."

Thus, to speak a language, one must know how the language is used in a social context. It is believed that each language has its own rules of usage as to when, how, and to what degree a speaker may impose a given verbal behavior on his or her conversational partner (Berns, 1990). Because of the influence or interference of their 
own cultural norms, it is hard for nonnative speakers to choose the forms appropriate to certain situations. For instance, in Chines culture, paying a compliment to someone obligates that person to give a negative response to show modesty, whereas in North America culture such a response might be both inappropriate and embarrassing. In English, How are you? Is usually considered a greeting, not a real question. In Kurdish language we also have such equivalent ( Chony?). However, in Hungarian, the phrase Hogy vagy? The meaning of this phrase depending on whether the speaker uses the informal or formal form. Thus, it may communicate genuine interest in the other speaker's well-being.

English phrases, such as greetings or invitations, are used in other languages, but often take on a different meaning. In Hangarian, for instance, Hello, in addition to being a greeting, is a leave-taking. Therefore, while it is perfectly acceptable in Hangarian to convey goodbye by saying hello, a native English speaker hearing hello is likely to be astonished by such leave-taking. In slang Arabic, we also use hello as a greeting and as a leave-taking.

It should be also mentioned that adult English speakers do not ordinarily address someone as Auntie or Uncle unless is genuine familial relationship of that sort. In Kurdish culture, however, children and young people use forms such as Kake, Dade, Mimi, Mame, Khalo, porie, to address older adults inside and outside of their family.

During the process of language teaching, teachers can present situations in which there are cultural misunderstandings that cause people to become offended, angry, and confused.

As a result of these differences, learners often have difficulty acquiring the pragmatic rules and functions that differ from their native language. In fact, language proficiency can not be complete without the knowledge of the appropriate pragmatic rules of the target language. According to Carrasquillo( 1994: 65), language proficiency is not a unidimensional construct but a multifaceted modality, consisting of various levels of abilities and domains. Hymes (1971) also assumes that EFL learners need to know not only the linguistic knowledge, but also the culturally acceptable ways of interacting with others in different situations and relationships.

\section{Learners' Conversational Interaction}

Conversation is the first interaction type to be learnt by human beings. Conversation is also the most basic of all genres, the primordial site of language use ( Schegloff (1996) cited in (shopen,2007:302). Whereas, Cutting (2002:28) defines conversation as a discourse mutually constructed and negotiated in time between speakers.

Brown and Yule (1983) and Slade (1986) agree that conversation is a listener- or person-oriented. As in other speaking tasks, a conversation requires the speaker to 473 | acadj@garmian.edu.krd Vol.5, No.4 (August, 2018) 
'face temporal constraints and the social pressures of face- to- face interaction'(Chafe, 1986:16).

Conversation is a truly communicative event which is a dynamic exchange in which linguistic competence must adapt itself to the total information input, both linguistic and paralinguistic (Savignon,1971, cited in Higgs and Clifford, 1982:58).

Richards (1983:118), on the other hand, affirms that conversations begin with greetings and progress through various ordered moves: the speaker's and hearer's roles are ascertained, topics are introduced, rights to talk are assumed, new topics are raised, and at the appropriate time the conversation is terminated in a suitable manner. Underhill( 1987:45) also believes that 'the speaker and the hearer have to take initiative, ask questions, or express disagreement in the conversation, all of which require a command of particular language features and which can be learnt.

Language learning evolves learning how to carry on conversation as well as learning how to communicate (Hatch, 1978: 63). In addition, Long ( 1983) suggested that if conversational adjustments in interaction help make input more comprehensible, and facilitate the EFL learning, then the linguistic and conversational adjustments that occur during interaction may promote language learning. These important claims, known as Long's interaction hypothesis, led to a great deal of work, including: relationships between conversational interaction and language comprehension, relationships between specific interactional processes and learning outcomes, and how interaction creates opportunities for learning. In Long's (1996), (as cited in (Mackey,2011:2)) updated version of the interactional hypothesis, he maintains that conversational interactional is highly beneficial because 'it connects input, internal learner capacities, particularly selective attention, and output in productive way.

Relatively, many previous studies such as (Gass and Varonis (1994) Swain (1995); and Oliver (1998) as cited in (Macky:2011:29) have examined the benefits of interactions between learners for promoting language development. In addition, these studies have indicated that during learners' conversational interactions, learners receive comprehensible input, opportunities to negotiate for meaning and receive others' feedback, and opportunities to produce modified out put.

\section{Procedures and the Experimental Design}

\subsection{The Experimental Design}

In order to achieve the aims of the present study, the researcher used the pre-post-test for two groups, an experimental group and a controlling group.

The experimental group is taught the conversation activities with the focus on the pragmatic competence. The researcher has enhanced their knowledge about the 
differences between the formal and informal forms in greetings and invitations. During the experiment, the students have shown the differences between their mothers' language (in our case the Kurdish language) and the English language as a foreign language.

On the other hand, the controlling group is taught the conversation activities by using the ordinary method.

\subsection{The Sample Selection}

The population of the present study is the first year students in the English department at the college of Languages and Human Sciences at Garmian University. There are two classes of the first year students, each one consisted of 27 students. Class (A) is taken as an experimental group, while class (B) is taken as a controlling group.

\subsection{The Instruction}

The instruction of the experiment has lasted six weeks. Started on the $21^{\text {st }}$ of January, 2018. The experiment of the present study has ended on $28^{\text {th }}$ of February, 2018. The researcher herself taught the experimental and control groups in order to control the teaching variable in the experiment.

\subsection{Instrument of the Study}

To assess the success of the present instruction, an instrument which comprises two achievement tests are used. Written test (see appendix A) and an oral test (see appendix B). the aim of these tests are to validate the hypothesis that developing the learners' pragmatic competence is very important for their EFL learning. As well as, it is believed that developing learners' pragmatic competence will positively effect their conversational interaction.

\subsubsection{Tests Construction}

The achievement tests are used to measure the extent of learner progress toward the achievement of the instructional objectives of a specific study as well as to evaluate the effectiveness of instruction (Harris, 1969: 3).

In fact, the researcher has constructed an oral test ( see appendix B). This test aims at developing the learners' pragmatic competence awareness and enhancing the learners' ability in their conversational interactions orally. Therefore, during the instruction short conversations are given to the students, and they are asked to expand the dialog by adding extra phrases and elements. The researcher writes the phrases on the board and play a CD concerned with oral conversations. The third edition of (Richards, 2005)1, 2.3 have been used during the instruction. The emphases will be on the effective using of the formal and informal greetings and invitations. 
In addition, the researcher has constructed a written achievement test. The aim of this test is to investigate the effect of developing learners' pragmatic competence through two kinds of speech acts; that is, expressive (greetings) and directives (invitations). In order to determine the amount of learning gain during instruction, the same achievement test is used as a pre test and post test. The test consisted of (4) questions, contains (42) items (see appendix A).

\subsubsection{The Scoring Scheme of the Test}

The researcher gave one mark for the correct answer of each item, and zero for the wrong one. The test consisted of 42 items. Thus, the highest mark for the test is 24 , while a zero is the lowest.

\subsubsection{Test Validity}

The validity of an item like the validity of a test is a complex quality. It is the degree to which it tests what it is said to test. However, there are four types of validity, that is, construct validity, empirical validity, content validity, and face validity. Accordingly, only content validity and face validity have been achieved.

\subsubsection{Content Validity}

According to Harris(1969: 19) the test has content validity if it is designed to measure the mastery of a specific skill or the content of a particular course of the study.

\subsubsection{Face Validity}

Face validity is secured if the list of items appears to measuring what it is intended to measure( Ebel,1972:78).

\subsubsection{The Pilot Administration of the Test}

The initial form of the test was given to (14) students, drawn from the same sample of the study. The aims of the pilot study is to

1) Determine the effectiveness of the items and secure the clarity of each item .

2) Estimate the time needed for answering the test completely.

3) Omit or modify the items that were not suitable for the students.

\subsubsection{Item Analysis}

The item analysis usually involves determining the level of difficulty and the discrimination power of each item of the test.

\subsubsection{Difficulty Level}

The difficulty level is calculated by determining the percentage of testers who answered the item correctly divided by the total number of the testers. By applying 
the difficulty level formula of each item in the test, it has been found that the difficulty level of each of the 42 test items ranges from (0.39) and (0.78). According to Madsen (1983:182), any item whose difficulty level ranges from 30 percent to 90 percent is acceptable. See table (1).

\subsubsection{Discrimination Power}

The discrimination power of the test is calculated by subtracting the number of the testers in the lower group who answered the item correctly from the number of the testers in the upper group who answered the item correctly and dividing the result by the number of the testers in either group. By applying the discrimination power formula of each item in the test, it has been found that the difficulty level of each of the 42 test items ranges from (0.21) and (0.85). Brown(1981:104) believes that any item is acceptable when its discrimination power is 20 percent and above. See table (1)

\subsection{Statistical Means}

To achieve the results of the present study, the researcher has used the following statistical means to calculate:

1) The difficulty level of each item has been achieved by the following formula:

$$
D L=\frac{H C+L C}{N}
$$

2) The discrimination power of each item has been achieved by the following formula:

$$
D P=\frac{R U-R L}{\frac{1}{2} T}
$$

3) The difference in the achievement of the students in the pre and post test and the difference between the control group and experimental group in the test, have been calculated by using the following formula:

$$
t=\frac{\overline{X_{1}}-\overline{X_{2}}}{S \sqrt{\frac{1}{n_{1}}+\frac{1}{n_{2}}}}
$$


Table ( 1 ) The Difficulty Level and the Discrimination Power of the Test

\begin{tabular}{|c|c|c|c|}
\hline Item & Difficulty Level & Item & Discrimination Power \\
\hline 1 & 0.71 & 1 & 0.57 \\
\hline 2 & 0.58 & 2 & 0.43 \\
\hline 3 & 0.46 & 3 & 0.21 \\
\hline 4 & 0.57 & 4 & 0.28 \\
\hline 5 & 0.39 & 5 & 0.35 \\
\hline 6 & 0.46 & 6 & 0.21 \\
\hline 7 & 0.53 & 7 & 0.21 \\
\hline 8 & 0.64 & 8 & 0.28 \\
\hline 9 & 0.57 & 9 & 0.85 \\
\hline 10 & 0.46 & 10 & 0.21 \\
\hline 11 & 0.53 & 11 & 0.21 \\
\hline 12 & 0.46 & 12 & 0.35 \\
\hline 13 & 0.60 & 13 & 0.35 \\
\hline 14 & 0.46 & 14 & 0.21 \\
\hline 15 & 0.53 & 15 & 0.35 \\
\hline 16 & 0.57 & 16 & 0.85 \\
\hline 17 & 0.78 & 17 & 0.43 \\
\hline 18 & 0.71 & 18 & 0.57 \\
\hline 19 & 0.78 & 19 & 0.43 \\
\hline 20 & 0.78 & 20 & 0.43 \\
\hline 21 & 0.64 & 21 & 0.71 \\
\hline 22 & 0.78 & 22 & 0.43 \\
\hline 23 & 0.57 & 23 & 0.85 \\
\hline 24 & 0.57 & 24 & 0.85 \\
\hline 25 & 0.78 & 25 & 0.43 \\
\hline 26 & 0.78 & 26 & 0.43 \\
\hline 27 & 0.46 & 27 & 0.21 \\
\hline 28 & 0.46 & 28 & 0.21 \\
\hline 29 & 0.46 & 29 & 0.35 \\
\hline 30 & 0.57 & 30 & 0.85 \\
\hline 31 & 0.57 & 31 & 0.85 \\
\hline 32 & 0.57 & 32 & 0.85 \\
\hline 33 & 0.71 & 33 & 0.57 \\
\hline 34 & 0.46 & 34 & 0.35 \\
\hline 35 & 0.46 & 35 & 0.21 \\
\hline 36 & 0.64 & 36 & 0.71 \\
\hline 37 & 0.64 & 37 & 0.28 \\
\hline 38 & 0.57 & 38 & 0.28 \\
\hline 39 & 0.71 & 39 & 0.57 \\
\hline 40 & 0.64 & 40 & 0.71 \\
\hline 41 & 0.71 & 41 & 0.57 \\
\hline 42 & 0.64 & 42 & 0.71 \\
\hline
\end{tabular}




\subsection{Results}

\subsubsection{The Achievement of Learners in the Pre-test}

The researcher has used this variable to equalize the subjects of the experimental and control groups in their previous knowledge concerning the material that would be taught during the instruction. Table (2) shows that the computed $t$-value is (0.299) and the tabulated t-value is (1.788) under (88) degrees of freedom and (0.05) level of significance. This indicates that there is no significance difference between the experimental and the control groups.

Table (2) Mean, Variance, and t-Value of the Pre Test Scores of the Two Groups

\begin{tabular}{|l|l|l|l|l|l|l|l|}
\hline Group & $\mathrm{N}$ & $\mathrm{X}-$ & \multirow{2}{*}{$\mathrm{S}^{2}$} & \multirow{2}{*}{ Df } & \multicolumn{2}{|l|}{$\mathrm{T}$ - value } & $\begin{array}{l}\text { Level of } \\
\text { Significance }\end{array}$ \\
\cline { 1 - 4 } & & & & & Computed & Tabulated & \\
Experimental & 20 & 10.793 & 18.507 & 88 & 0.299 & 1.788 & 0.05 \\
\hline Control & 20 & 10.501 & 20.521 & & & & \\
\hline
\end{tabular}

\subsubsection{The Post Test}

As a matter of fact, the same test which is used in the pre-test has been used as a posttest. This procedure aims to indicate which group of the learners has achieved better.

At the end of the experiment, the results which obtained from the test have been analyzed to determine whether there is any significant difference between the mean scores of the experimental and the control groups in the total scores of the test. Table ( 3 ) shows that the computed t-value is (6.351) and the tabulated t-value is (3.112) under (88) degrees of freedom and (0.001) level of significance. This indicates that there is a significance difference between the experimental and the control groups. This difference is in favour of the experimental group.

Table (3) Mean, Variance, and t-Value of the Post Test Scores of the Two Groups

\begin{tabular}{|l|l|l|l|l|l|l|l|}
\hline Group & $\mathrm{N}$ & $\mathrm{X}$ & \multirow{2}{*}{$\mathrm{S}^{2}$} & \multirow{2}{*}{$\mathrm{Df}$} & \multicolumn{2}{|l|}{$\mathrm{T}$ - value } & $\begin{array}{l}\text { Level of } \\
\text { Significance }\end{array}$ \\
\cline { 1 - 4 } & & & & & Computed & Tabulated & \\
\hline Experimental & 20 & 29.972 & 73.234 & 88 & 6.351 & 3.112 & 0.001 \\
\hline Control & 20 & 15.277 & 50.099 & & & & \\
\hline
\end{tabular}

\subsubsection{The Experimental Group's Progress}

The researcher has compared the scores of the experimental group in the pre-test and the post-test. It is found out that the computed t-value is (12.363), which indicates that there is a significance difference between the pre test and post test scores of the experimental group as compared with the tabulated t-value, which is (3.089) at (0.001) level of difference under (44) degrees od freedom. See table(4). 
Table (4) t-Test Statistics for the Experimental Groups' Progress

\begin{tabular}{|l|l|l|l|l|l|l|l|l|l|}
\hline Group & $\mathrm{N}$ & $/ \mathrm{d}$ & $\mathrm{d} \sum$ & $\mathrm{d}^{2} \sum$ & $\sigma$ & $\mathrm{Df}$ & \multicolumn{2}{|l|}{$\mathrm{T}$ - value } & $\begin{array}{l}\text { Level of } \\
\text { Significance }\end{array}$ \\
\hline Pre & 20 & 20.153 & 899 & 20995 & 4.031 & 44 & 12.363 & 3.089 & 0.001 \\
\hline Post & 20 & & & & & & & & Computed \\
\hline
\end{tabular}

\section{Conclusion}

In order to communicate effectively in the target language, learners of English need to develop pragmatic competence, which can be accomplished through pragmatic instruction in the classroom, particularly in the oral English class. With the raise of pragmatic awareness, it is expected that learners will acquire the competence and their target language performance will improve.

The teaching of pragmatic competence can be very constructive and beneficial to students for developing communicative competence in the target language. The previous studies as well as the present research paper have enlightened that pragmatic knowledge does not seem to come along naturally in EFL classrooms, so teachers need to try to contribute to the developing of learners' pragmatic competencies through instruction. Hence, it has been concluded that:

1) The goal of this study is to ascertain how the explicit teaching of some aspects of pragmatic competence (greetings and invitations) affected students' performance.

2) Developing the students' pragmatic competence affects their conversational interaction.

3) The instruction has pointed the fact that language proficiency can not be complete without knowledge of the appropriate pragmatic rules of the target language.

4) Pragmatic competence can be developed in the classroom through a range of situations and activities.

5) Speech has a performative function, and our learners' ability take part successfully in verbal exchanges of any kind, depends on knowing how to manage and behave in conversation.

\section{Recommendations}

On the basis of the results of the present research paper, the following recommendations are suggested:

1. Teachers and textbook writers should tap all channels that leading to effective language learning.

2. Pragmatic competence is an aspect that needs special attention and instruction. In order to provide effective instruction, it is necessary for teachers of EFL to carefully 480 $\quad$ acadj@garmian.edu.krd Vol.5, No.4 (August, 2018) 
examine the factors, conditions, and components that underlie speaking effectiveness. Effective instruction derived from the careful analysis of this area, together with sufficient language input and speech-promotion activities will gradually help learners to compose suitable conversations and speak English fluently and appropriately.

3) Refreshing courses should be designed for the students to give them firsthand experience in issues of pragmatic competence.

4) Teachers should do their best to deepen the students' understanding by letting them discover the pragmatic competence rules themselves.

5) It is also believed that pragmatic rules that are different from or nonexistent in the students' first language need to be given more emphasis.

6) Besides the teachers who are to explore and enhance materials from the textbook, material developers and curriculum designers should also include pragmatic awareness in the books and curricula.

\section{References}

Austin, J. L. (1962). How to do Things with Words. Oxford: Oxford University Press.

Bardovi-Harling, K., B. S. Hartford, R. Mahan-Taylor, M. J. Morgan and D.

W. Reynolds (1996). Developing Awareness: Closing the Conversation.

Oxford: Oxford University Press.

Berns, Mm (1990). Contexts of Competence: Social and Cultural

Considerations in Communicative Language Teaching. New York:

Plenum Press.

Bonvillian, N. (1993) Language, Culture and Communication: The Meaning of Messages. Englewood Cliff: Printice-Hall.

Boxer, D. and L. Picking. (1995). Problems in the Presentation of Speech Acts in ELT Materials: the Case of Complaints. ELT Journal 49(1):44-58.

Brown, F. G. (1981). Classroom Achievement. New York: Holt, Rinehart and Winston. Inc.

Brown, G., and Yule, G. (1983). Teaching the Spoken Language: An Approach Based on the Analysis of Conversational English. New York: Cambridge University Press.

Brown, H. D. (1994). Principles of Language Learning and Teaching. Englewood Cliffs, NJ: Prentice Hall.

Cannale, M. (1983). From Communicative Competence to Communicative Language Pedagogy. London: Longman.

Carrasquillo, A. L. (1994) Teaching English as a Second Language: A Resource Guide. New York: Grand Publishing. 
Chafe, W. (1986). Writing in the perspective of spoken. London: Sage Publications.

Clark, Urszula. (2007). Studying Language: English in Action. London: Palgrave Mamillan.

Crystal,David (1987). What is Linguistic? $4^{\text {th }}$ edition. London: Edward Arnold.

Cutting, J. (2002). Pragmatics and Discourse: A Resource Book for

Students. London: Routledge.

Dimitracopoulou, I. (1990). Conversational Competence and Social

Development. Cambridge: Cambridge University Press.

Ebell, Robert, L. (1972). Essential of Educational Measurement. New Jersey: Printice-Hall.

Edwards, M. and K. sizer.(2001). Opening and Closing the Conversationhow course book dialog can be implemented in the classroom. Nov ELTy 8(2): 55-66.

Hariss, David, P.( 1969). Testing English as a Second Language. New York: MacGraw Hill.

Higgs, T, and Clifford, R. (1982). The Push Towards Communication. Skoki, IL: National. Textbook Company.

Hymes, D. (1971). On Communicative Competence. Phildelphia: University of Pennsylvania Press.

Jacob, Mey, I. (2001). Pragmatics: An Introduction. Malden, Massachussets; Blackwell Publishers.

Kasper, G.(1997). Can Pragmatics Competence be Taught?. University of Hawaii, Second Language Teaching and Curriculum Center. www.nflrc. hawaii.edu/Net-work/NW06/

Long, M. H. (1983) 'Natine Speaker/ non- native Speaker Conversation and Negotiation of Comprehensible Input'. Applied Linguistics 4/2: 126-141.

Mackey, Alison. (2011). Conversational Interaction in Second Language Acquisition. Oxford: Oxford University Press.

Madsen, Harolds. (1983). Techniques in Testing. London: Oxford University Press.

Oliver, R. (1998). 'Negotiation of Meaning in Child Interactions'. The Modern Language Journal 82/3: 372-386.

Richards, Jack C. (1983). Communicative Needs in Foreign Language Learning. ELT Journal, 37(2), 111-120. 
Richards, Jack C. and Willy A. Renandya. (2002) Methodology in Laguage Teaching: An Anthology of Current Practice. Cambridge: Cambridge University Press.

Richards, Jack C. , Jonathan Hull, and Susan Proctor. (2005). Interchange 1. $3^{\text {rd }}$ edition. Cambridge: Cambridge University Press.

Richards, Jack C. , Jonathan Hull, and Susan Proctor. (2005). Interchange 2. $3^{\text {rd }}$ edition. Cambridge: Cambridge University Press.

Richards, Jack C. , Jonathan Hull, and Susan Proctor. (2005). Interchange 3. $3^{\text {rd }}$ edition. Cambridge: Cambridge University Press.

Rossner, R. and Bolitho, R. (1990). Current of Change in English Language Teaching. Oxford: Oxford University Press.

Schegloff, Emanuel A., Elinor Ochs, and Sandra A. Thompson. (1996) Interaction and Grammar. Cambridge: Cambridge University Press.

Shopen, Timothy. (2007) language Typologyand Syntactic Description. $2^{\text {nd }}$ edition. Volume II. Cambridge: Cambridge University Press.

Slade, D. (1986). Teaching Casual Conversation to Adult ESL Learners. Prospect, 2(1), 68-87.

Underhill, N. (1987). Testing Spoken Language. Cambridge: Cambridge University Press.

Wright, A. (1987). Roles of Teachers and Learners. Oxford: Oxford University Press.

Yule, George. (1988). The Study of Language. Cambridge: Cambridge University Press.

Yule, George. (1996). Pragmatics. New York: Oxford University Press

Yule, George. (2006). The Study of Language. Cambridge: Cambridge University Press. 
اللفة هي وسيلتنا الاكثر قوة للتخاطب عند استخدامها بصورة صحيحة. واذا لم يتم ذلك بـالشكل الصحيح, فهي تعتبر مجرد عائق للتخاطب. علاوة على ذلك, فان للفة دور حساس في حياتنا. ولكي يبرع الطلاب ويتمكنوا من اللغة الانكليزية,

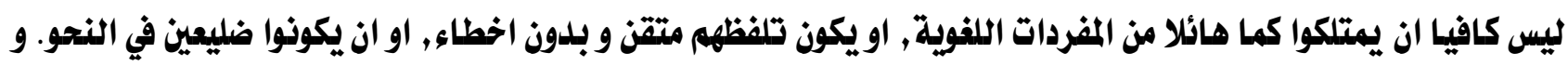

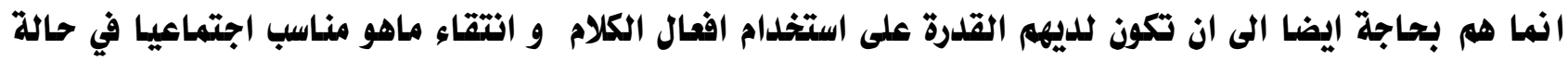

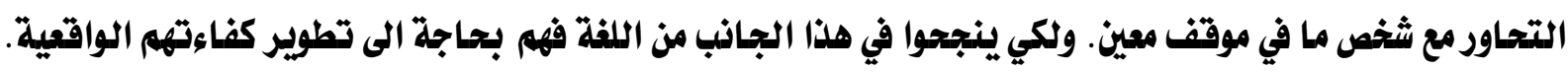
ومن خلال السنوات العديلدة في مجال تدريس طلبة الجامعات في مختلف المراحل, قد لوحظ ان الطلاب يفتقروذ الى الحدل

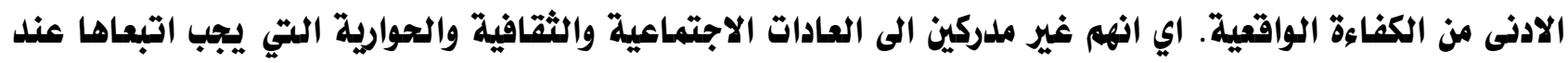

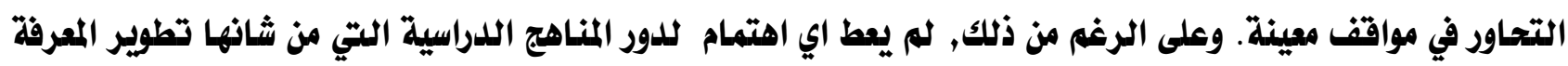

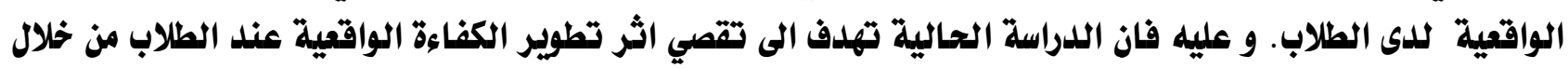

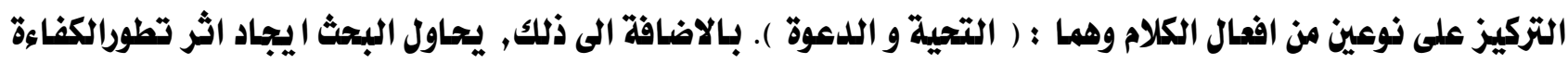

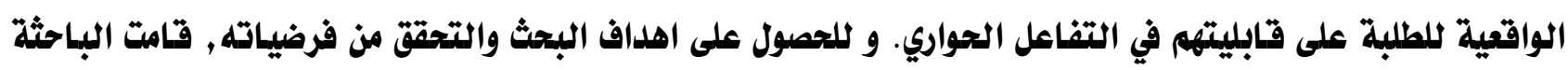
ببناء اختبار تحصيلي ( قبلي - بعدي ). اما عينة البحث, فهم طلاب قسم اللفة الانكليزية في كلية اللفات والعلوم الانسانية, في جامعة كرميان. 
Appendix ( A ) Pre- Post-Test

Q1: A// Which expressions would you use to accept an invitation or refuse an invitation? Check ( $\sqrt{ }$ ) the correct answer.

\begin{tabular}{|l|l|l|}
\hline Expressions & Accepting & Refusing \\
\hline 1. I'm really sorry. & & \\
\hline 2. Great. & & \\
\hline 3. Sounds like fun. & & \\
\hline 4. I've made other plans. & & \\
\hline 5.I won't be able to make it. & & \\
\hline 6. I'm busy. & & \\
\hline 7. Thanks a lot. & & \\
\hline 8. I'd love to. & & \\
\hline
\end{tabular}

$\mathbf{B} / /$ Use the expressions in part $\mathbf{A}$ to accept or refuse these invitations. Offer an excuse if you refuse.

1. Sue: Would you like to come a photography class with me tomorrow?

Jim:

2. Bill: Someone told me there was a good Australian movie at the Plaza. Do you want to see it with me this weekend?

Tina:

3. Ary: A friend asked me to go shopping after class. Do you want to join us?

Elfy:

4. Tara: I have tickets to the baseball game on Saturday. Would you like to go?

Aven:

5. Sary: Would you like to come over for dinner tomorrow night?

Mina:

6. Nina: Would you like to go to a pop concert with me this weekend?

Fem:

7. Lara: We're going to go horseback riding. Do you want to join us?

Mary:

8. Jim: I signed up for a scuba diving class. Do you want to be with me?

Tom:

Q2: Complete the following conversation.

Anna: Tom, what's up?

Tom: Hi Anna. Nothing much. I'm just hanging out. What's up with you?

Anna: It's a good day. I'm feeling fine.

Tom: Would you to night?

Anna: What time shall we meet?

Tom : At

Anna: That sounds great.

Tom: OK. Let's meet

Anna: That sounds fine.

Q3: A// Which expressions would you use to express formal and informal greetings? Check $(\sqrt{ })$ the correct answer.

\begin{tabular}{|l|l|l|}
\hline Expressions & formal & Informal \\
\hline $1 . \mathrm{Hi}$. & & \\
\hline
\end{tabular}




\begin{tabular}{|l|l|l|}
\hline 2. What's up? & & \\
\hline 3. It was a pleasure seeing you. & & \\
\hline 4. How's life been treating you? & & \\
\hline 5. Good afternoon Mr. Danyal. & & \\
\hline 6. Hello teacher. & & \\
\hline 7.Good to see you. & & \\
\hline 8. It's always a pleasure to see you. & & \\
\hline
\end{tabular}

B//Give suitable responses to the following formal and informal greetings:

1) Anny: Good morning Sir. It was a pleasure seeing you.

Mr.Smith:

2) Ms. Anna: Hello Ms. Anderson. How are you today?

Ms. Anderson:

3) Kathy: Where have you been hiding?

Danny:

4) Zed: What's new?

Ralf:

5) Jeff: Oh, hello Chris. How are you doing?

Chris:

6) Mr. Brown: What have you been up to all these years?

Dr. Clarence:

7) Mr. Arthur: How's everything going?

Ms. Tulip:

8) Dorothy: How's life been treating you?

Erick:

Q4: Complete the following conversation.

John:

Alan: Good morning. ?

John: thank you ?

Alan: I'm fine. Thank you for asking.

John: ?

Alan: Yes, I do. Do you have a meeting as well?

John: Yes. It will be a very long today. 


\section{Appendix ( B )}

\section{Oral test}

During this test the students will practice the conversation orally and they will be asked to compose imaginary conversations about a specific topics. The researcher will encourage the students to use formal and informal expressions in their conversations. The students are asked to perform the conversations with their peers. The focus will be on the ability of the students to use greetings and invitation in the correct way as well as their appropriate choice of the formal and informal forms of greetings and invitations that required by the situation.

\section{First week}

Greeting a person you haven't seen for a long time formally.

\section{Second week}

Greeting a person you haven't seen for a long time informally.

\section{Third week}

Mrs. and Mr. Gardi have invited you to attend their son' birthday. You are: Mr. Ramyar. Give a formal reply to accept or refuse their invitation.

\section{Fourth week}

You friend Chawan has invited you to attend his wedding ceremony. You are: Dylan. Give an informal reply to accept or refuse his invitation. 